\title{
Incidence of pneumococcal and varicella disease in HIV-infected children and adolescents in the UK and Ireland, 1996-2011
}

Vaccination is an excellent method for prevention of life-threatening diseases. Children infected with human immunodeficiency virus (HIV) have an increased susceptibility to, and develop more severe complications from, all infections ${ }^{1}$, even in the era of combination antiretroviral therapy (cART). Streptococcus pneumoniae is the most common cause of bacterial pneumonia and is responsible for significant morbidity and mortality in children and adults infected with HIV ${ }^{2}$. The significant burden of varicella-associated disease in children with HIV infection is also widely recognised $^{3}$.

HIV-infected children often have impaired immune responses to vaccines compared with their HIV-uninfected counterparts ${ }^{4}$. However, studies in children with stable HIV disease have demonstrated safety and generally protective responses to the pneumococcal conjugate ${ }^{5,6}$ and varicella ${ }^{7}$ vaccines. Administration of these vaccines is therefore now advised for HIV-infected children in addition to the routine immunizations given to all children and a recommended schedule has recently been published ${ }^{4}$. However, in the UK and many countries worldwide, HIVinfected children often do not receive all recommended vaccines and therefore remain vulnerable to disease ${ }^{8,9}$. Data on rates of routine vaccination of HIV-infected children in the UK are not available in the CHIPS database; however, a 2009 audit of vaccine coverage among HIV-infected children attending 3 London clinics revealed that rates of immunization were extremely low, with only $28 \%$ receiving the pneumococcal conjugate vaccine (PCV7, introduced in 2006) and none receiving a varicella vaccine ${ }^{10}$.

This study aimed to define the burden of infections due to invasive pneumococcal disease (IPD) and varicella zoster infections (VZ) in HIV-infected children in the UK and Ireland over the last 16 years. These data will, in turn, provide a baseline measure for assessing the impact of recent guidelines on the use of these vaccines in this population ${ }^{4}$. 


\section{MATERIALS AND METHODS}

The Collaborative HIV Paediatric Study (CHIPS) has been described in detail elsewhere ${ }^{11,12}$. Briefly, it is a multicentre observational cohort study of virtually all HIV-infected children receiving pediatric care in the UK and Ireland. All hospitalizations, defined as any admission for in-patient care for any duration or cause among children aged $<18$ years, and deaths, were reviewed. The primary cause of hospitalization was categorised according to the ICD-10 coding system (Appendix 1). Admissions with the stated primary cause of IPD, VZ, or all-cause lower respiratory infections between 1 January 1996 and 31 December 2011 were extracted from the CHIPS database.

Microbiological confirmation of cases of IPD, and serotype where available, were obtained through direct contact with the reporting clinicians. Similarly, cause of death and whether the death occurred in hospital were verified with the clinician. Characteristics of children with VZ and IPD admissions were described, and incidence rates of first admissions per 1000 patient years (PYs) were calculated by ART status at the time of the admission. In the case of multiple admissions, only characteristics at the time of the first admission were used. ART status was categorized as: on combination ART for at least 6 months prior to the admission (cART defined as any combination regimen of 3 or more antiretroviral drugs); or not on cART (i.e. no ART, mono or dual therapy, or cART for less than 6 months). At least 6 months of cART was chosen as an adequate duration of ART to ensure viral suppression and CD4 reconstitution ${ }^{13}$ before the opportunistic infection was acquired. If a child had started cART it was assumed that $s /$ he remained on cART during follow-up without interruption. Chi square tests were used to compare categorical variables, $t$ tests to compare means, and Wilcoxon rank-sum and non-parametric equality of medians tests to compare medians from two and three groups respectively. All analyses were conducted using STATA 12 (College Station, Texas).

Rates of admissions for pneumococcal, varicella and zoster disease for all children (HIVuninfected as well as HIV-infected) aged 0-14 years in England were acquired from Hospital Episode Statistics (HESonline ${ }^{14}$ ) and the Office for National Statistics ${ }^{15}$ for the period January 1999 to December 2011, using relevant ICD-10 codes (Appendix 1). These were used as the best available group for comparison with the CHIPS cohort ${ }^{16,17}$. 


\section{RESULTS}

A total of 1,785 children were followed in the CHIPS cohort between 1 January 1996 and 31 December 2011 and 3,905 hospital admissions among 1,119 children were recorded over this period. Of these, 23 admissions in 22 children were due to IPD, 107 admissions in 99 children were due to varicella and 89 admissions in 79 children were due to herpes zoster; a combined total of 196 admissions in 172 children for varicella zoster (VZ). Three children had both IPD and VZ admissions; for two, the VZ admission preceded the IPD admission by at least 7 months, and one child had both infections concurrently. A total of 156 admission days were attributable to IPD and 873 days for VZ. Combined admissions for both diseases accounted for around $5 \%$ of all admissions each year (Figure 1). IPD admissions were generally low over the whole time period, while admissions with VZ appear to have declined in absolute numbers (similar to trends in the overall number of hospital admissions in the time period ${ }^{11}$ ), but not as a proportion of all admissions.

Table 1 presents characteristics of children admitted with IPD or VZ compared to those without IPD or VZ admissions. There was no difference in sex, route of HIV transmission, place of birth, median age at HIV diagnosis or CD4 count / \% at HIV diagnosis between the three groups. There was only one admission of VZ that was the child's presenting illness at HIV diagnosis, all other admissions of IPD and VZ were in children with established HIV-infection. A higher proportion of children admitted with IPD or VZ were diagnosed with HIV at a later clinical stage (CDC stage $B$ or $C$ ) compared to those with no admissions $(36.8 \%, 29.7 \%$ and $22.1 \%$ respectively, $p=0.030)$. Children with episodes of IPD and VZ were more likely to have started cART during follow-up compared to children with no admissions $(94.7 \%, 91.3 \%$ and $80.2 \%$, $\mathrm{p}=0.004$ ). For those starting $\mathrm{cART}$, median age and CD4\% at the start of cART were similar across the three groups $(p=0.164)$.

Table 2 shows characteristics of children at first admission for IPD or VZ by CART status at admission. For IPD, $3(15.8 \%)$ children had taken cART for at least 6 months prior to the admission, and 16 (84.2\%) had not. For VZ, 59 (34.3\%) had taken cART for at least 6 months and $113(65.7 \%)$ had not. For both IPD and VZ, median age at first admission was higher in children on cART compared to those not taking cART (IPD $14.5 \vee 5.7$ years, $p=0.025$; VZ $10.5 \mathrm{v}$ 6.0 years, $p<0.001)$. Although not significant, IPD admissions were more common in later calendar years for all children in CHIPS regardless of cART status $(p=0.705)$. For VZ, a higher proportion of admissions for children not on cART were in earlier years, whilst admissions in those on cART were more common in later calendar years $(p<0.001)$. There was no difference in duration of admission by CART status for IPD or VZ. For IPD and VZ admissions, there was no significant difference between median CD4\% or count at admission among those on cART 
compared to those not on CART; however for VZ, median viral load was significantly lower in the cART group (3.9 v 4.5, $\mathrm{p}=0.029)$.

In 4 of the 22 children with IPD the pneumococcal serotype (ST) was confirmed: one case of $9 \mathrm{~V}$, one of $19 \mathrm{~F}$, and 2 cases of $23 \mathrm{~F}$.

There were no deaths associated with hospitalization due to IPD but 2 cases where disseminated varicella was associated with death, one of which was the child's first presentation of HIV. There were 2 other deaths that were recorded by CHIPS but occurred without hospital admission: a 2-year old child died from pneumococcal disease with previous exposure to cART but was not on ART at death (1996); and a 6-year old died during an episode of chicken pox and was subsequently diagnosed with HIV (2004).

Incidence rates per 1000 person years (PYs) for all admissions of IPD, varicella and zoster are presented in Table 3, along with rates for all children in England aged 0-14 years in a similar time period. Incidence rates and rate ratios for all three infections were much higher for HIVinfected children not on cART than those on CART, and rates were also higher for those on cART compared to all children in England. For example, for zoster, the incidence rate for HIVinfected children not on cART was 12.2 per 1000 PYs (95\% Cl 9.0-16.3), compared to 3.5 (95\% $\mathrm{Cl} 2.4-5.0)$ for those on cART, and $0.03(95 \% \mathrm{Cl} 0.03-0.04)$ for all children in England. In addition, the hospitalization incidence rate for all-cause lower respiratory infections in HIVinfected children was 46.1 cases per $1000 \mathrm{PYs}$ (95\% Cl 39.7-53.2) for those not on cART and 6.4 (95\% Cl 4.8-8.2) for those on cART. This is 1.7 -fold higher than for all children aged $0-14$ years in England (3.8/1000 PYs) and 12-fold higher than the incidence in HIV-infected children not on CART. 


\section{DISCUSSION}

In this study we found a much higher incidence rate of IPD and VZ hospitalization in HIVinfected children in the UK and Ireland over the last 15 years compared to the general population of children, suggesting a considerable burden of morbidity from potentially vaccinepreventable infections in this group. The majority of this burden appears to be related to VZ disease although it is apparent that the rate of admission has declined over the last 15 years. This may partly reflect changing demographics as many now enter the cohort as older children because they are born overseas ${ }^{11}$, and because there are fewer infected infants born in the UK and Ireland due to effective prevention of mother-to-child transmission. Although admissions for VZ in children not on CART have steadily declined, likely due to the trend towards earlier commencement of cART, admissions for VZ in children on cART remains static, a rate that may not necessarily reflect clinical need as it may be confounded by the clinician's increased propensity for admitting a HIV-infected child. The small but apparent increase in pneumococcal admissions may reflect less complete reporting in the earlier years of the cohort since data from 1996-2000 was acquired from retrospective reporting ${ }^{12}$.

Overall there was no discernible trend in age or CD4\% at HIV diagnosis between children with IPD/VZ disease and those with no IPD/VZ admissions, and similarly no difference in age or CD4\% at the start of CART. Although numbers are small, CDC stage at HIV diagnosis was more advanced in children who were subsequently admitted with IPD and VZ, raising the question of whether these children were more immunocompromised than the rest of the cohort. Although there was no significant difference in CD4\% at the time of commencing cART for the three groups, this measure may not adequately reflect CD4 subpopulations, such as memory and naïve cells, which may differ between individuals with similar CD4 cell counts and have different functional properties ${ }^{18}$.

The majority of children who did have IPD or VZ admissions were not on cART at the time of their admission, and the increased rates of admission for all three infections in children not taking cART is clear, a finding which is also reported in adult studies ${ }^{19}$. Given that there was a higher proportion with $\mathrm{CDC}$ stage $\mathrm{B} / \mathrm{C}$ disease at diagnosis in the children with IPD/VZ admissions, it is conceivable that earlier introduction of cART might have prevented these infections. There was no evidence for a difference in duration of IPD and VZ admissions by cART status, although numbers were small.

The varicella vaccine has been available in the UK since 2002 for use in seronegative healthcare workers and families who live with an immunocompromised individual but not recommended for children with HIV ${ }^{20}$. Studies from the USA have demonstrated VZ vaccine 
safety in children with CD4\% $>15 \%$, and effectiveness of $82 \%$ against varicella, and $100 \%$ against herpes zoster over median 4.4 years follow up ${ }^{7}$. Although recent evidence suggests VZ vaccination cannot completely prevent episodes of herpes zoster, it has been shown to be less likely to occur after vaccination than after natural infection ${ }^{21}$. The recently updated Paediatric European Network for Treatment of AIDS and Children's HIV Association (PENTA/CHIVA) guidelines published in $2012^{4}$ now reflect this evidence and recommend the VZ vaccine be routinely used in HIV-infected children in Europe. The burden of VZ in this population in the UK is clear from our analysis and emphasises the importance of this recommendation.

Three deaths attributed to pneumonia occurred in CHIPS, and although no organism was identified pneumococcus is the commonest cause of bacterial pneumonia. The true burden of pneumococcal disease is likely to be under-estimated in both HIV-infected and uninfected children since the aetiology of hospitalized pneumonia cases is often undetermined. Streptococcus pneumoniae has been identified as the causative organism in $31 \%$ of adult community-acquired pneumonias (CAP) in the $\mathrm{UK}^{22}$ and in up to $89 \%$ of children with $\mathrm{CAP}^{23}$. Therefore, the incidence of all-cause lower respiratory infections requiring hospital admission in children taking CART in the CHIPS cohort (6.4/1000 PYs) might be more representative of the total burden of IPD in this population.

The 7-valent pneumococcal conjugate vaccine (PCV7) was introduced into the routine UK schedule in $2006^{18}$ and was superseded by the 13-valent vaccine (PCV13) in 2010. The conjugate vaccines have generally replaced the 23-valent polysaccharide pneumococcal vaccine (PPV23) which was previously recommended in children over 2 years in special risk groups, such as children with HIV ${ }^{24}$. There is good evidence to support the immunogenicity of the conjugate vaccines in both children with and without HIV-infection ${ }^{6,25,26}$. However, we know from audit data that the use of PCVs in this group may be sub-optimal. Since the introduction of PCV7 in the UK there has been a significant reduction in the incidence of IPD in all children ${ }^{27}$; although we haven't shown a reduction in the CHIPS cohort. The reasons for this are unclear; unfortunately it is not known whether these children have been vaccinated, how long after vaccinations IPD occurred, or which serotypes were responsible for the majority of these infections (only 4 of 22 ST were identified and all are PCV7 serotypes). It is expected that children with HIV would benefit both through direct protection as well as through herd immunity although it is possible that serotype replacement, which has been well documented in the UK population, might have a greater adverse impact on certain populations than on others ${ }^{28}$. It is important that in the future data on vaccination status and responsible STs are collected for all children in at-risk groups who develop IPD to enable fine-tuning of vaccine recommendations if required. 
One example of this is recommendations around the timing of booster doses. Despite optimal primary vaccination there is a well-recognized yet variable decline in protective antibody concentrations over time in HIV-infected children. Rates as low as $5 \%$ protection at a median of six years have been reported for measles ${ }^{29}, 43 \%$ at one year for $\mathrm{Hib}^{30}, 38 \%$ at eight months for tetanus $^{31}$, and $48 \%$ at five years for the pneumococcal vaccine ${ }^{32}$. Further studies are needed to improve our understanding of antibody decline to guide recommendations for re-vaccination and boosters. While vaccine-induced antibody responses are probably dependent on CD4 T-cell function, recent data suggest that HIV RNA viral load at vaccination can also correlate with vaccine failure ${ }^{26,33}$. In light of on-going studies into vaccine safety, immunogenicity and effectiveness it is vital that vaccination guidelines are both well-defined yet dynamic in response to robust, high-quality research.

The CHIPS cohort is an invaluable resource for cross-sectional and longitudinal data to optimize the management of HIV-infected children living in the UK and Ireland. However, this study is likely to provide an underestimate of the burden of infections due to these vaccine preventable infections; for example, CHIPS does not capture the burden of illness being managed in the community, reflected in the 3 deaths in the database that occurred out of hospital. In addition, this paper does not describe children who died very soon after HIV-presentation, therefore before they entered the CHIPS cohort. Anecdotally there were two cases in recent years of children who presented with advanced HIV and died in hospital from confirmed pneumococcal meningitis before they entered CHIPS. Finally, the database does not capture data on vaccine uptake nor adherence, and we recognise these limitations.

This descriptive study highlights the increased risk of admission with IPD or VZ disease in HIVinfected children compared to their uninfected peers, a risk which is increased in children who have not commenced cART. Earlier initiation of cART combined with vaccination is probably required to optimize protection against these infections. This study provides evidence to support attempts to improve routine vaccination uptake as well as promoting the recent PENTA/CHIVA guidelines ${ }^{4}$ recommending varicella vaccination for children with stable HIV. It is the most complete study of this nature to date and also serves as baseline data for future surveillance studies of IPD and VZ disease in this vulnerable group. 


\section{REFERENCES}

1. Alarcón JO, Freimanis-Hance L, Krauss M, Reyes MF, Cardoso CA, Mussi-Pinhata MM, Cardoso E, Hazra For The Nisdi Pediatric Study Group 2011. Opportunistic and other infections in HIV-infected children in Latin America compared to a similar cohort in the United States. AIDS Res Hum Retroviruses 2012;28:282-288.

2. Feikin DR, Feldman C, Schuchat A, Janoff EN: Global strategies to prevent bacterial pneumonia in adults with HIV disease. Lancet Infect Dis 2004;4:445-455.

3. Wood SM, Shah SS, Steenhoff AP, Rutstein RM. Primary varicella and herpes zoster among HIV-infected children from 1989 to 2006. Pediatrics 2008;21:e150-6.

4. Menson E, Mellado MJ, Bamford A, Castelli G, Duiculescu D, Marczynska M, Navarro M, Scherpbier H, Heath PT. The Pediatric European Network for Treatment of AIDS (PENTA) Vaccines Group, PENTA Steering Committee and Children's HIV Association (CHIVA). Guidance on vaccination of HIV-infected children in Europe. HIV Med 2012. DOI:10.1111/j.1468-1293.2011.00982.

5. Abzug MJ, Pelton SI, Song LY, Fenton T, Levin MJ, Nachman SA, Borkowsky W, Rosenblatt HM, Marcinak JF, Dieudonne A, Abrams EJ, Pathak I. Paediatric AIDS Clinical Trials Group P1024 Protocol Team. Immunogenicity, safety, and predictors of response after a pneumococcal conjugate and pneumococcal polysaccharide vaccine series in human immunodeficiency virus-infected children receiving highly active antiretroviral therapy. Pediatr Infect Dis J 2006;25:920-9.

6. Madhi SA, Adrian P, Cotton MF, Mclntyre JA, Jean- Philippe P, Meadows S, Nachman S, Käyhty $\mathrm{H}$, Klugman KP, Violari A on behalf of the CIPRA 4 team. Effect of HIV infection status and anti-retroviral treatment on quantitative and qualitative antibody responses to pneumococcal conjugate vaccine in infants. J Infect Dis. 2010 August 15; 202(3): 355361. doi:10.1086/653704.

7. Son M, Shapiro ED, LaRussa P, Neu N, Michalik DE, Meglin M, Jurgrau A, Bitar W, Vasquez M, Flynn P, Gershon AA. Effectiveness of varicella vaccine in children infected with HIV. J Infect Dis 2010;201:1806-10.

8. Myers C, Posfay-Barbe KM, Aebi C, Cheseaux JJ, Kind C, Rudin C, Nadal D, Siegrist CA; Pediatric Infectious Disease Group of Switzerland (PIGS); Swiss Mother and Child HIV Cohort Study (MoCHIV). Determinants of vaccine immunity in the cohort of human 
immunodeficiency virus-infected children living in Switzerland. Pediatr Infect Dis $\mathrm{J}$ 2009;28:996-1001.

9. Fernández-lbieta M, Ramos-Amador JT, Auñón-Martín I. HIV-infected children vaccination coverage and safety in a Western European cohort: a retrospective study. Int J STD AIDS 2007;18:351-3.

10. Zinna S, Bamford A, Cunnington A, Kampmann B, Lyall E, Menson E, Heath P. Immunization status of children with HIV: failure to protect a vulnerable population. HIV Med. 2011 Aug;12(7):447-8.

11. Judd A, Doerholt K, Tookey PA, Sharland M, Riordan A, Menson E, Novelli V, Lyall EG, Masters J, Tudor-Williams G, Duong T, Gibb DM; Collaborative HIV Paediatric Study (CHIPS); National Study of HIV in Pregnancy and Childhood (NSHPC). Morbidity, mortality, and response to treatment by children in the United Kingdom and Ireland with perinatally acquired HIV infection during 1996-2006: planning for teenage and adult care. Clin Infect Dis. 2007;45:918-24.

12. Gibb DM, Duong T, Tookey PA, et al. Decline in mortality, AIDS, and hospital admissions in perinatally HIV-1 infected children in the United Kingdom and Ireland. BMJ 2003;327:1019.

13. Picat MQ, Lewis J, Musiime V, Prendergast A, Nathoo K, Kekitiinwa A, Nahirya Ntege $P$, Gibb DM, Thiebaut R, Walker AS, Klein N, Callard R. Predicting patterns of long-term CD4 reconstitution in HIV-infected children starting antiretroviral therapy in sub-Saharan Africa: a cohort-based modelling study. PLoS Med. 2013 Oct;10(10):e1001542. doi: 10.1371/journal.pmed.1001542. Epub 2013 Oct 29.

14. Hospital Episode Statistics, UK: Accessed on 14.09.2012 http://www.hesonline.nhs.uk/Ease/servlet/ContentServer?sitelD=1937\&categoryID=214

15. Office for National Statistics, UK: Access on 14.09 .2012 http://www.ons.gov.uk/ons/publications/re-reference-tables.html?edition=tcm\%3A77231847

16. Smith MP, Evans E, White C. Update to the methodology used to calculate health expectancies. Health Stat Q. 2013 Spring;56:1. Epub 2013 Feb 19.

17. Pedace L. Child Wellbeing in England, Scotland and Wales: Comparisons and variations. http://www.familyandparenting.org/Resources/FPI/Documents/ChildWellbeingInEnglandS 
cotlandandWales.pdf. Accessed on 19.02.2014

18. Douek DC, Picker LJ, Koup RA. T cell dynamics in HIV-1 infection. Annu Rev Immunol. 2003;21:265-304. Epub 2001 Dec 19.

19. Yin Z, Rice B, Waight P, Miller E, George R, Brown A, Smith R, Slack M, Delpech V. Invasive pneumococcal disease among HIV-positive individuals, 2000-2009. AIDS 2011 Jan;26(1):87-94.

20. Salisbury D, Ramsey M, Noakes K. Immunisation against disease: The Green Book. Department of Health, 2007.

21. Gershon AA, Gershon MD. Pathogenesis and Current Approaches to Control of Varicella-Zoster Virus Infections. Clin Microbiol Rev. 2013 Oct;26(4):728-743.

22. Melegaro A, Edmunds WJ, Pebody R, Miller E, George R. The current burden of pneumococcal disease in England and Wales. J Infect. 2006 Jan;52(1):37-48.

23. Djuretic T, Ryan MJ, Miller E, Fairley CK, Goldblatt D. Hospital admission in children due to pneumococcal pneumonia in England. J Infect. 1998;37(1):54-58.

24. A Finn, R Booy, R Moxon, M Sharland, P Heath. Should the new pneumococcal vaccine be used in high-risk children? Arch Dis Child 2002; 87:18-21.

25. Nachman S, Kim S, King J, Abrams EJ, Margolis D, Petru A, Shearer W, Smith E, Moye J, Blanchard S, Hawkins E, Bouquin P, Vink P, Benson M, Estep S, Malinoski F; Pediatric AIDS Clinical Trials Group Study 292 Team. Safety and immunogenicity of a heptavalent pneumococcal conjugate vaccine in infants with human immunodeficiency virus type 1 infection. Pediatrics 2003;112(1 Pt 1):66-73.

26. Nunes MC, Madhi SA. Safety, immunogenicity and efficacy of pneumococcal conjugate vaccine in HIV-infected individuals. Human Vaccines \& Immunotherapeutics 8:2, 161173; February 2012; G 2012 Landes Bioscience

27. Andrews N, Waight PA, Borrow R, Ladhani S, George RC, Slack MP, Miller E. Using the Indirect Cohort Design to Estimate the Effectiveness of the Seven Valent Pneumococcal Conjugate Vaccine in England and Wales. PLoS One. 2011; 6(12).

28. Tasslimi A, Sison EJ, Story E, Alland D, Burday M, Morrison S, Nalmas S, Smith S, Thomas PA, Wenger P, Sinha A. Disappearance of vaccine-type invasive pneumococcal 
disease and emergence of serotype 19A in a minority population with a high prevalence of human immunodeficiency virus and low childhood immunization rates. Clin Vaccine Immunol. 2009 Aug;16(8):1256-9. doi: 10.1128/CVI.00140-09. Epub 2009 Jun 10.

29. Melvin AJ, Mohan KM. Response to immunization with measles, tetanus, and Haemophilus influenzae type b vaccines in children who have human immunodeficiency virus type 1 infection and are treated with highly active antiretroviral therapy. Pediatrics 2003;111(6 Pt 1):e641-4.

30. Gibb D, Giacomelli A, Masters J, Spoulou V, Ruga E, Griffiths H, Kroll S, Giaquinto C, Goldblatt D. Persistence of antibody responses to Haemophilus influenzae type $b$ polysaccharide conjugate vaccine in children with vertically acquired human immunodeficiency virus infection. Pediatr Infect Dis J 1996;15:1097-101.

31. Al-Attar I, Reisman J, Muehlmann M, Mclntosh K. Decline of measles antibody titers after immunization in human immunodeficiency virus-infected children. Pediatr Infect Dis $\mathrm{J}$ 1995;14:149-51.

32. Madhi SA, Klugman KP, Kuwanda L, Cutland C, Käyhty H, Adrian P. Quantitative and qualitative anamnestic immune responses to pneumococcal conjugate vaccine in HIVinfected and HIV-uninfected children 5 years after vaccination. J Infect Dis. 2009;199:1168-76.

33. Reed AC. Siemieniuk DB. Gregson M, Gill J. The persisting burden of invasive pneumococcal disease in HIV patients: an observational cohort study. BMC Infectious Diseases 2011, 11:314. 


\section{ACKNOWLEDGEMENTS}

\section{Author contributions:}

$\mathrm{PH}$ and KDoe conceived and supervised the study. AJ and KDon performed the statistical analyses. HP and IO contacted the clinicians. SL assisted with acquisition of data. HP and AJ interpreted the data and prepared the manuscript. All authors have contributed to the writing of the paper and have approved the final draft for submission.

\section{Financial support:}

The National Study of HIV in Pregnancy and Childhood receives core funding from the Health Protection Agency. The Collaborative HIV Paediatric Study is funded by the NHS (London Specialized Commissioning Group) and has received additional support from Bristol-Myers Squibb, Boehringer Ingelheim, GlaxoSmithKline, Roche, Abbott, and Gilead Sciences. The views expressed in the publication are those of the authors and not necessarily those of the Health Protection Agency, the London NHS Specialized Commissioning Group, the Medical Research Council, or any additional funders.

\section{CHIPS acknowledgements}

We thank Jeannie Collins and the CHIPS Steering Committee for their helpful comments on this paper, notably Hermione Lyall and Caroline Foster.

Committees and participants (in alphabetical order):

CHIPS Steering Committee: K Butler, S Donaghy, C Foster, N Klein, H Lyall, E Menson, C Peckham, A Riordan, F Shackley, M Sharland, D Shingadia, PA Tookey, G Tudor-Williams, S Welch.

MRC Clinical Trials Unit: T Childs, J Collins, D Dobson, K Doerholt, DM Gibb, L Harper, D Johnson, A Judd, J Kenny, AS Walker.

National Study of HIV in Pregnancy \& Childhood, UCL Institute of Child Health: M CortinaBorja, PA Tookey. 
We thank the staff, families \& children from the following hospitals who participate in CHIPS (in alphabetical order):

Republic of Ireland: Our Lady's Children's Hospital Crumlin, Dublin: K Butler, A Walsh.

UK: Birmingham Heartlands Hospital, Birmingham: Y Heath, S Welch; Blackpool Victoria Hospital, Blackpool: N Laycock; Bristol Royal Hospital for Children, Bristol: A Finn, , J Bernatoniene, F Manyika L Hutchison; Calderdale Royal Hospital, Halifax: G Sharpe; Central Middlesex Hospital, London: M Le Provost, A Williams; Chase Farm Hospital, Middlesex; Chelsea and Westminster Hospital, London: D Hamadache, EGH Lyall, P Seery; Coventry \& Warwickshire University Hospital, Coventry: P Lewis, K Miles; Derbyshire Children's Hospital, Derby: B Subramaniam; Derriford Hospital, Plymouth: J Ferguson, P Ward; Ealing Hospital, Middlesex: K Sloper; Eastbourne District General Hospital, Eastbourne: G Gopal; Glasgow Royal Hospital for Sick Children, Glasgow: C Doherty, R Hague; Great Ormond St Hospital for Children, London: M Clapson, J Flynn, DM Gibb, N Klein, V Novelli, D Shingadia; Halliwell Children's Centre, Bolton: P Ainsley-Walker; Harrogate District Hospital, Harrogate: P Tovey; Hillingdon Hospital, London; Hinchingbrooke Hospital, Huntingdon: H Dixon; Homerton University Hospital, London: D Gurtin; Huddersfield Royal Infirmary, Huddersfield: JP Garside; Ipswich Hospital, Ipswich: J Gould; James Cook Hospital, Middlesbrough: A Fall; John Radcliffe Hospital, Oxford: D Kelly, S Segal; King's College Hospital, London: C Ball, S Hawkins; Leeds General Infirmary, Leeds: P Chetcuti, M Dowie; Leicester Royal Infirmary, Leicester: M Green; Luton and Dunstable Hospital, Luton: M Eisenhut; Mayday University Hospital, Croydon: J Handforth; Milton Keynes General Hospital, Milton Keynes: PK Roy; Newcastle General Hospital, Newcastle: J Clarke, A Pickering; Newham General Hospital, London: S Liebeschuetz; Ninewells Hospital and Medical School, Dundee: T Lornie; Norfolk \& Norwich Hospital, Norwich: C Kavanagh; North Manchester General Hospital, Manchester: C Murphy, T Tan; North Middlesex Hospital, London: J Daniels, Y Lees; Northampton General Hospital, Northampton: F Thompson; Northwick Park Hospital Middlesex; M Le Provost, A Williams; Nottingham City Hospital, Nottingham: J Smith, A Smyth; Queen Alexandra Hospital, Portsmouth: A Freeman; Queen 
Elizabeth Hospital, Woolwich: T Banjoko; Raigmore Hospital, Inverness: T Reddy; Royal Alexandra Hospital, Brighton: K Fidler; Royal Belfast Hospital for Sick Children, Belfast: S Christie; Royal Berkshire Hospital, Reading: A Gordon; Royal Children's Hospital, Aberdeen: D Rogahn; Royal Cornwall Hospital, Truro: S Harris; Royal Devon and Exeter Hospital, Exeter: A Collinson; Royal Edinburgh Hospital for Sick Children, Edinburgh: J Mok; Royal Free Hospital, London: S McKenna, V Van Someren; Royal Liverpool Children's Hospital, Liverpool: C Benson, A Riordan; Royal London Hospital, London: A Riddell; Royal Preston Hospital, Preston: R O'Connor; Salisbury District General Hospital, Salisbury: N Brown; Sheffield Children's Hospital, Sheffield: J Hobbs, F Shackley; Southampton General Hospital, Southampton: SN Faust, J Hancock; St George's Hospital, London: K Doerholt, S Donaghy, K Prime, M Sharland, S Storey; St Luke's Hospital, Bradford: S Gorman; St Mary's Hospital, London: EGH Lyall, C Monrose, G Tudor-Williams, S Walters; St Thomas' Hospital (Evelina Children's Hospital), London: R Cross, E Menson; Torbay Hospital, Torquay: J Broomhall; University Hospital Lewisham, London: D Scott, J Stroobant; University Hospital of North Staffordshire, Stoke On Trent: P McMaster; University Hospital of Wales, Cardiff: J Evens, T Gardiner; West Cumberland Hospital, Whitehaven: D Lee; Wexham Park, Slough: R Jones; Whipps Cross Hospital, London: K Gardiner; Whittington Hospital, London; Wythenshawe Hospital, Manchester: D Denning. 
Figure 1: Admissions of invasive pneumococcal disease (IPD) and varicella zoster disease (VZ): number and percentage of all admissions by year, $1996-2011$.

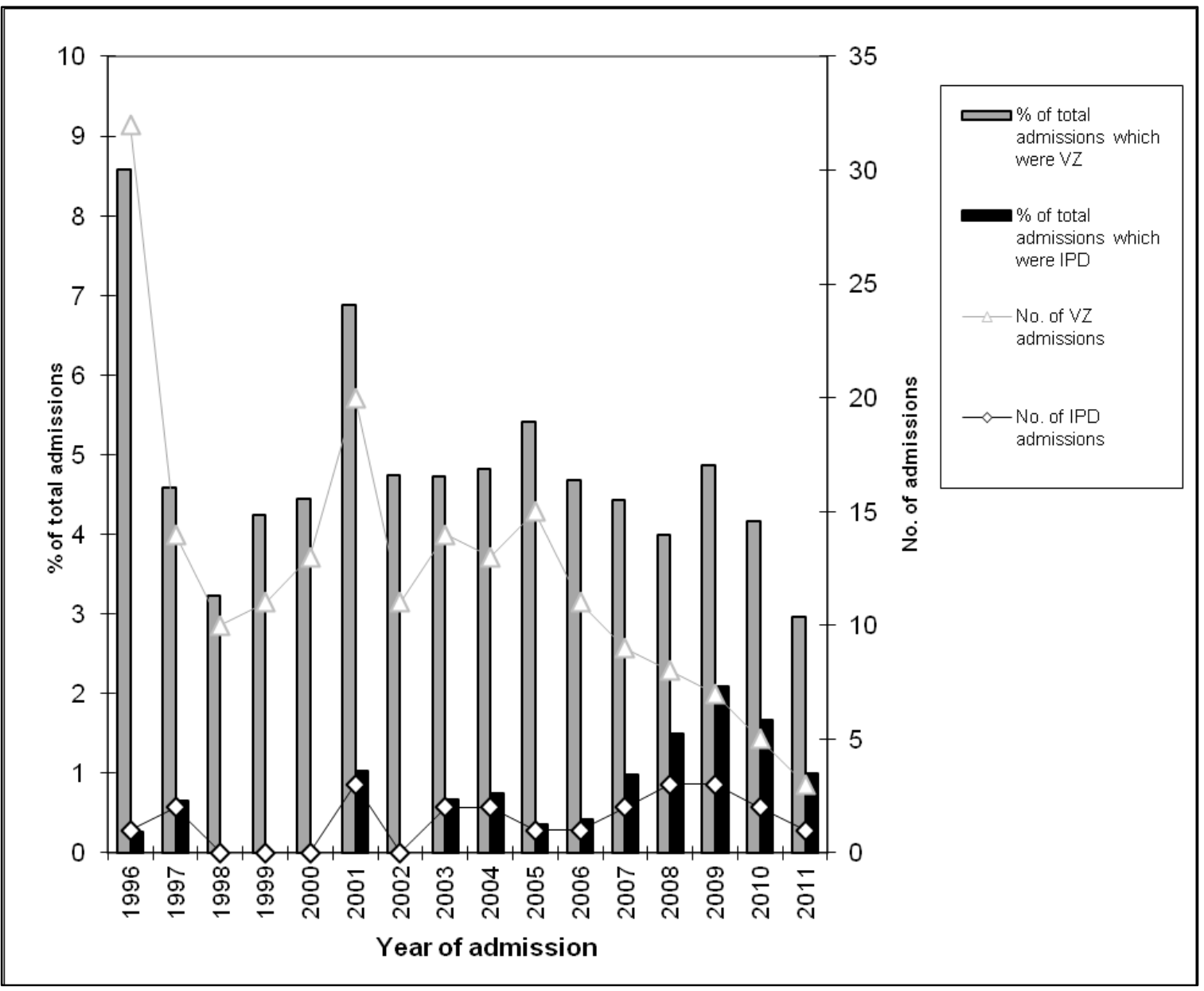


Table 1: Characteristics of HIV-infected children in the UK/Ireland according to cause of hospital admission.

\begin{tabular}{|c|c|c|c|c|}
\hline & $\begin{array}{l}\text { No IPD or VZ } \\
\text { admissions } \\
(n=1600)\end{array}$ & $\begin{array}{l}\text { IPD admissions } \\
(n=19)\end{array}$ & $\begin{array}{l}\text { VZ admissions } \\
\quad(n=172)\end{array}$ & p-value \\
\hline & \multicolumn{3}{|c|}{$\mathrm{n}(\%)$ or median [IQR] } & \\
\hline Female sex & $821(51.3)$ & $11(57.9)$ & $96(55.8)$ & 0.462 \\
\hline Vertical HIV transmission & $1,506(94.1)$ & $18(94.7)$ & 165 (95.9) & 0.705 \\
\hline Born in UK/Ireland & 709 (44.3) & $7(36.8)$ & $90(52.3)$ & 0.152 \\
\hline Age at HIV diagnosis (years) & $3.6[0.6-8.2]$ & $3.4[1.7-8.2]$ & $3.0[0.7-6.9]$ & 0.802 \\
\hline CD4\% at HIV diagnosis & $21[12-30]$ & 19 [15-28] & $21[14-28]$ & 0.929 \\
\hline CD4 count at HIV diagnosis & 590 [281-1109] & $943[510-1076]$ & 610 [269-1136] & 0.576 \\
\hline $\begin{array}{l}\text { CDC stage at HIV diagnosis } \\
\text { NA/A } \\
\text { B/C }\end{array}$ & $\begin{array}{l}1,246(77.9) \\
354(22.1)\end{array}$ & $\begin{array}{l}12(63.2) \\
7(36.8)\end{array}$ & $\begin{array}{l}121(70.4) \\
51(29.7)\end{array}$ & 0.030 \\
\hline $\begin{array}{l}\text { ART status ever } \\
\text { Naive } \\
\text { Mono/ dual therapy } \\
\text { cART }\end{array}$ & $\begin{array}{c}278(17.4) \\
39(2.4) \\
1,283(80.2)\end{array}$ & $\begin{array}{c}1(5.3) \\
0(0) \\
18(94.7)\end{array}$ & $\begin{array}{c}10(5.8) \\
5(2.9) \\
157(91.3)\end{array}$ & 0.004 \\
\hline $\begin{array}{l}\text { Age at start of cART (years) } \\
\text { for those on cART }\end{array}$ & $6.6[2.3-10.7]$ & $7.7[5.1-10.9]$ & $6.6[3.8-10.7]$ & 0.637 \\
\hline $\begin{array}{l}\text { CD4\% at start of cART for } \\
\text { those on cART }\end{array}$ & 15 [9-22] & $17[14-24]$ & 15 [9-22] & 0.164 \\
\hline CD4 count at start of cART & 330 [164-659] & $449[287-756]$ & $312[173-646]$ & 0.569 \\
\hline
\end{tabular}

$\mathrm{IPD}=$ Invasive pneumococcal disease, $\mathrm{VZ}=$ varicella zoster disease, $\mathrm{cART}=$ combination of 3 antiretroviral drugs for at least 6 months, IQR = interquartile range. 
Table 2: Characteristics of pneumococcal (IPD) and varicella (VZ) first admissions by cART status at admission.

\begin{tabular}{|c|c|c|c|c|c|c|}
\hline & \multicolumn{3}{|c|}{ IPD $(n=19)$} & \multicolumn{3}{|c|}{ VZ $(n=172)$} \\
\hline & $\begin{array}{c}\text { Not on cART } \\
(n=16)\end{array}$ & $\begin{array}{l}\text { On cART } \\
(n=3)\end{array}$ & $p$-value & $\begin{array}{l}\text { Not on cART } \\
(n=113)\end{array}$ & $\begin{array}{c}\text { On cART } \\
(n=59)\end{array}$ & $p$-value \\
\hline & \multicolumn{2}{|c|}{$\mathrm{n}(\%)$ or median [IQR] } & & \multicolumn{2}{|c|}{$\mathrm{n}(\%)$ or median [IQR] } & \\
\hline $\begin{array}{l}\text { Age at first } \\
\text { admission (years) }\end{array}$ & $\begin{array}{c}5.7 \\
{[3.5-10.8]}\end{array}$ & $\begin{array}{c}14.5 \\
{[11.7-16.0]}\end{array}$ & 0.025 & $\begin{array}{c}6.0 \\
{[3.6-10.0]}\end{array}$ & $\begin{array}{c}10.5 \\
{[6.6-13.5]}\end{array}$ & $<0.001$ \\
\hline $\begin{array}{l}\text { Year of first } \\
\text { admission } \\
1996-2000 \\
2001-2005 \\
2006-2011\end{array}$ & $\begin{array}{l}3(18.8) \\
5(31.3) \\
8(50.0)\end{array}$ & $\begin{array}{c}0(0.0) \\
1(33.3) \\
2(66.7)\end{array}$ & 0.705 & $\begin{array}{l}56(49.6) \\
39(34.5) \\
18(15.9)\end{array}$ & $\begin{array}{l}13(22.0) \\
26(44.1) \\
20(33.9)\end{array}$ & 0.001 \\
\hline $\begin{array}{l}\text { First admission } \\
\text { duration (days) }\end{array}$ & $\begin{array}{c}5.0 \\
{[3.5-6.0]}\end{array}$ & $\begin{array}{c}3.0 \\
{[3.0-8.0]}\end{array}$ & 0.572 & $\begin{array}{c}5.0 \\
{[2.0-7.0]}\end{array}$ & $\begin{array}{c}4.0 \\
{[2.0-6.0]}\end{array}$ & 0.657 \\
\hline $\begin{array}{l}\text { CD4\% at first } \\
\text { admission }\end{array}$ & $\begin{array}{c}17.0 \\
{[13.5-23.0]}\end{array}$ & $\begin{array}{c}36.0 \\
{[19.0-39.0]}\end{array}$ & 0.060 & $\begin{array}{c}19.0 \\
{[12.0-25.0]}\end{array}$ & $\begin{array}{c}22.0 \\
{[12.0-29.0]}\end{array}$ & 0.122 \\
\hline $\begin{array}{l}\text { CD4 count at first } \\
\text { admission }\end{array}$ & $\begin{array}{c}572 \\
{[425-805]}\end{array}$ & $\begin{array}{c}629 \\
{[287-1213]}\end{array}$ & 0.773 & $\begin{array}{c}425 \\
{[280-782]}\end{array}$ & $\begin{array}{c}521 \\
{[238-987]}\end{array}$ & 0.509 \\
\hline $\begin{array}{l}\log _{10} \text { viral load at } \\
\text { first admission }\end{array}$ & $\begin{array}{c}4.5 \\
{[4.3-5.4]}\end{array}$ & $\begin{array}{c}2.1 \\
{[1.7-5.1]}\end{array}$ & 0.166 & $\begin{array}{c}4.5 \\
{[3.6-5.0]}\end{array}$ & $\begin{array}{c}3.9 \\
{[2.6-4.8]}\end{array}$ & 0.029 \\
\hline
\end{tabular}

IPD = Invasive pneumococcal disease, $\mathrm{VZ}=$ varicella zoster disease, $\mathrm{cART}=$ combination of 3 antiretroviral drugs for at least 6 months, IQR $=$ interquartile range.

Table 3: Incidence rates (95\% confidence intervals) per 1000 person years and relative risk of all admissions for pneumococcal (IPD) and varicella disease for HIV-infected children on and off cART compared to all children.

\begin{tabular}{|l|c|c|c|}
\hline & IPD & Varicella & Zoster \\
\hline $\begin{array}{l}\text { Admission rate of HIV-infected children aged 0- } \\
17 \text { years not on cART in UK/Ireland, 1996-2011 }\end{array}$ & $4.7(2.8-7.4)$ & $19.8(15.6-24.7)$ & $14.1(10.6-18.3)$ \\
\hline $\begin{array}{l}\text { Admission rate of HIV-infected children aged 0- } \\
17 \text { years on cART in UK/Ireland, 1996-2011 }\end{array}$ & $0.5(0.2-1.3)$ & $3.4(2.3-4.8)$ & $3.8(2.7-5.3)$ \\
\hline $\begin{array}{l}\text { Admission rate for all children aged 0-14 years } \\
\text { in England, 1999-2011 }\end{array}$ & $\begin{array}{c}0.03 \\
(0.025-0.039) \\
{[n=3,705]}\end{array}$ & $\begin{array}{c}0.23 \\
(0.18-0.27) \\
{[n=26,421]}\end{array}$ & $\begin{array}{c}0.03 \\
{[0.025-0.031)} \\
{[n=3,287]}\end{array}$ \\
\hline $\begin{array}{l}\text { Rate ratio of the three admission rates above*: } \\
\text { (HIV-infected not on cART/on cART/all children) }\end{array}$ & $156.7 / 16.7 / 1$ & $86.1 / 14.8 / 1$ & $470 / 126.7 / 1$ \\
\hline
\end{tabular}

${ }^{*}$ Admission rate ratio for all hospital admissions of IPD, varicella and herpes zoster among HIV-infected children taking or not taking cART, compared with admissions among HIV-uninfected children. IPD = Invasive pneumococcal disease, CART $=$ combination of 3 antiretroviral drugs for at least 6 months. 
Supplementary digital content legend:

Appendix 1: ICD-10 codes used to acquire admission data for HIV-uninfected children aged 0 to 14 years in England ${ }^{12}$.

\begin{tabular}{|c|c|c|}
\hline Pneumococcal disease & Varicella disease & Herpes Zoster disease \\
\hline G00.1 Pneumococcal meningitis & B01.0 Varicella meningitis & B02.0 Zoster encephalitis \\
J13.X Pneumonia due to & B01.1 Varicella encephalitis & B02.1 Zoster meningitis \\
Streptococcus pneumoniae & B01.2 Varicella pneumonia & B02.2 Zoster with other nervous \\
A40.3 Septicaemia due to & B01.8 Varicella with other & system involvement \\
Streptococcus pneumoniae & complications & B02.3 Zoster ocular disease \\
& B01.9 Varicella without & B02.7 Disseminated zoster \\
& complication & B02.8 Zoster with other \\
& & complications \\
& & B02.9 Zoster without \\
& & complication \\
\hline
\end{tabular}

